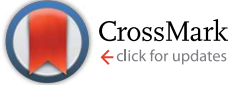

Cite this: J. Mater. Chem. A, 2015, 3 , 19754

Received 20th July 2015

Accepted 17th August 2015

DOI: $10.1039 / \mathrm{c} 5 \mathrm{ta} 05548 \mathrm{~b}$

www.rsc.org/MaterialsA

\section{Structural, electrochemical and magnetic properties of a novel $\mathrm{KFeSO}_{4} \mathrm{~F}$ polymorph $\dagger$}

\author{
Laura Lander, ${ }^{\text {ab }}$ Gwenaëlle Rousse, ${ }^{\text {abc }}$ Artem M. Abakumov, ${ }^{d}$ Moulay Sougrati, ${ }^{\text {e }}$ \\ Gustaaf van Tendeloo ${ }^{d}$ and Jean-Marie Tarascon ${ }^{\star a b c}$
}

\section{Introduction}

Over the last two decades, lithium ion batteries have become the most important electrical energy storage technology due to their high energy densities. They dominate the portable electronics market and are of great appeal for electric vehicle and grid storage technologies. Nevertheless, prior to reaching such applications, improvements must be made in terms of safety, cost and sustainability. Meeting such demands calls for the development of new cathode materials. In the quest for such new materials, Fe-based polyanionic compounds have been intensively studied. Among them, low-cost $\mathrm{LiFePO}_{4}$ is at present the most praised one for the next generation EV batteries. ${ }^{1}$ Nevertheless, one of its drawbacks is nested in its operating potential of solely $3.45 \mathrm{Vvs.} \mathrm{Li}^{+} / \mathrm{Li}^{0}$. Thus, recent research has been focused on the development of new Fe-based polyanionic

\footnotetext{
${ }^{a}$ FRE 3677 "Chimie du Solide et Energie", Collège de France, 11 Place Marcelin Berthelot, 75231 Paris Cedex 05, France. E-mail: jean-marie.tarascon@ college-de-france.fr

${ }^{b}$ Réseau sur le Stockage Electrochimique de l'Energie (RS2E), FR CNRS, 3459, France 'Sorbonne Universités - UPMC Univ Paris 06, 4 Place Jussieu, 75005 Paris, France ${ }^{d}$ EMAT, University of Antwerp, Groenenborgerlaan 171, 2020 Antwerp, Belgium ${ }^{e}$ ICGM Institut Charles Gerhardt - CNRS and Université Montpellier, Place Eugène Bataillon, 34095 Montpellier, France

$\dagger$ Electronic supplementary information (ESI) available: Symmetry analysis for magnetic structure determination, results of symmetry analysis, DSC analysis, in situ XRD, neutron powder diffraction pattern, EDX, and CIF file of $\mathrm{KFeSO}_{4} \mathrm{~F}$. See DOI: $10.1039 / \mathrm{c} 5$ ta05548b
}

materials having higher $\mathrm{Fe}^{3+} / \mathrm{Fe}^{2+}$ redox potentials while still preserving cost and sustainability benefits. ${ }^{2}$

Pursuing this path and applying Goodenough's concept of the inductive effect, ${ }^{3}$ our group successfully exploited the replacement of $\left(\mathrm{PO}_{4}\right)^{3-}$ by a more electronegative $\left(\mathrm{SO}_{4}\right)^{2-}$, which led to the synthesis of a variety of new polyanionic materials among which monoclinic $\mathrm{Li}_{2} \mathrm{Fe}\left(\mathrm{SO}_{4}\right)_{2}$ for instance shows a potential of $3.83 \mathrm{~V} v s$. $\mathrm{Li}^{+} / \mathrm{Li}^{0}{ }^{4,5}$ To further increase the ionocovalency of the metal-anion bond, highly electronegative $\mathrm{F}^{-}$ was added to the structural framework and a series of fluorosulfate compounds $\mathrm{Li} M S O_{4} \mathrm{~F}(M=\mathrm{Fe}, \mathrm{Mn}, \mathrm{Co}, \mathrm{Ni})$ were recently obtained..$^{6-9} \mathrm{~A}$ member of this family, $\mathrm{LiFeSO}_{4} \mathrm{~F}$, was shown to crystallize either in a tavorite or triplite crystal structure, with the latter reversibly reacting with $\mathrm{Li}^{+}$at a potential of $3.9 \mathrm{~V}$, the highest potential so far reported for a $\mathrm{Fe}^{3+} / \mathrm{Fe}^{2+}$ redox couple in an inorganic compound.

In order to widen the rich crystal chemistry offered by $\mathrm{Li}$ based 3D-metal fluorosulfates, we explored the replacement of $\mathrm{Li}$ by other alkali metals and prepared additional $A \mathrm{FeSO}_{4} \mathrm{~F}$ phases. One of the so-discovered phases is $\mathrm{KFeSO}_{4} \mathrm{~F}$, which adopts the structure reported for $\mathrm{KTiOPO}_{4}$ (hereafter referred to as KTP) in the orthorhombic Pna2 ${ }_{1}$ space group. ${ }^{10,11}$ We have reported that $\mathrm{K}^{+}$ions can be electrochemically removed from this phase to form a new " $\mathrm{FeSO}_{4} \mathrm{~F}$ " polymorph, which, due to its large open structure, can electrochemically take up various alkali cations such as $\mathrm{Li}^{+}, \mathrm{Na}^{+}$and $\mathrm{K}^{+} .{ }^{11}$ At this stage, bearing in mind that sulfate-based iron compounds are prone to polymorphism (e.g. tavorite/triplite $\mathrm{LiFeSO}_{4} \mathrm{~F}^{6-9}$ tavorite/layered $\mathrm{LiFeSO}_{4} \mathrm{OH},{ }^{12,13}$ and orthorhombic/monoclinic $\left.\mathrm{Li}_{2} \mathrm{Fe}\left(\mathrm{SO}_{4}\right)_{2}{ }^{4,5}\right)$, 
it was tempting to search for polymorphism in $\mathrm{KFeSO}_{4} \mathrm{~F}$ as well. We herein report the successful synthesis via a low temperature route of a new $\mathrm{KFeSO}_{4} \mathrm{~F}$ polymorph, which crystallizes in a monoclinic unit cell and shows an antiferromagnetic ordering at $22 \mathrm{~K}$. We find via ionic conductivity and electrochemical measurements that nearly $0.8 \mathrm{~K}^{+}$can be removed from this polymorph, which can afterwards reversibly take up $0.5 \mathrm{Li}^{+}$at an average voltage of $3.7 \mathrm{~V} v$ s. $\mathrm{Li}^{+} / \mathrm{Li}^{0}$.

\section{Synthesis}

We have previously prepared orthorhombic $\mathrm{KFeSO}_{4} \mathrm{~F},{ }^{1 \mathbf{1 1}}$ from stoichiometric amounts of $\mathrm{FeSO}_{4}$ and $\mathrm{KF}$, that were heated at $380{ }^{\circ} \mathrm{C}$ for several days in an evacuated sealed quartz tube to prevent the risk of $\mathrm{Fe}^{2+}$ to $\mathrm{Fe}^{3+}$ oxidation in an ambient environment. Nevertheless, in the process of setting the aforementioned protocol, we experienced, when operating at lower temperatures $\left(265-320^{\circ} \mathrm{C}\right)$, the presence of an unidentified secondary phase within our samples. Various synthesis conditions such as annealing temperatures, heating times, precursors, heating container, etc. together with different synthesis routes (ionothermal and microwave) were tested in order to obtain a sample solely containing our secondary phase. This survey led to the establishment of an optimized synthesis protocol enlisting three steps. First of all, $\mathrm{FeSO}_{4} \cdot 7 \mathrm{H}_{2} \mathrm{O}$ (Alfa Aesar, $\geq 99.0 \%$ ) was purified and dehydrated following a previously reported procedure in order to form $\mathrm{FeSO}_{4} \cdot \mathrm{H}_{2} \mathrm{O}^{14}$ The so-obtained monohydrate was further dehydrated through a heat treatment at $270{ }^{\circ} \mathrm{C}$ under an $\mathrm{Ar} / \mathrm{H}_{2}$ atmosphere for $20 \mathrm{~h}$. Anhydrous $\mathrm{FeSO}_{4}$ is then ball milled for 20 minutes with a slight excess $(3 \%)$ of $\mathrm{KF}$ (Sigma-Aldrich, $\geq 99.0 \%$, dried at $70{ }^{\circ} \mathrm{C}$ overnight under vacuum), in an Ar-filled ball-mill jar using a Spex 8000 vibratory miller and a ball-to-powder ratio of around 20. Afterwards, this mixture was pressed into a pellet and annealed in an under vacuum sealed quartz tube at $310{ }^{\circ} \mathrm{C}$ for three days to produce a pure monoclinic $\mathrm{KFeSO}_{4} \mathrm{~F}$ phase. The chemical composition of the compound was confirmed by EDX measurements using a Hitachi S-3400N SEM (ESI Table S2 $\dagger$ ). We experienced that any deviation from the aforementioned milling conditions usually led to samples contaminated by traces of orthorhombic $\mathrm{KFeSO}_{4} \mathrm{~F}$. Therefore, the purity of the precursors is systematically verified by X-ray diffraction after initial ball-milling in order to make sure that no orthorhombic $\mathrm{KFeSO}_{4} \mathrm{~F}$ started to form. A similar synthesis protocol was used to stabilize the homologous monoclinic $\mathrm{KMSO}_{4} \mathrm{~F}$ phases with $M$ $=\mathrm{Mn}$ and $\mathrm{Cu}$ with the only difference that the ball-milled composites made of the corresponding sulfate precursors $\mathrm{MSO}_{4}$ and $\mathrm{KF}$ were heated at $280{ }^{\circ} \mathrm{C}$ for 2 days for $\mathrm{Mn}$ and to $400{ }^{\circ} \mathrm{C}$ for 4 days for $\mathrm{Cu}$. It is worth mentioning here that even though the existence of the monoclinic polymorph was observed for $\mathrm{Mn}$ and $\mathrm{Cu}$ by powder X-ray diffraction, we could never obtain them as a pure phase due to the presence of minute amounts of $\mathrm{K}_{2} \mathrm{Mn}_{2}\left(\mathrm{SO}_{4}\right)_{3}$ and $\mathrm{K}_{2} \mathrm{Cu}_{3} \mathrm{O}\left(\mathrm{SO}_{4}\right)_{3}$ secondary phases, respectively. Moreover, our attempts to stabilize the Co- and Ni-based analogs failed whatever the applied synthesis route. In short, from the aforementioned various synthesis trials we could

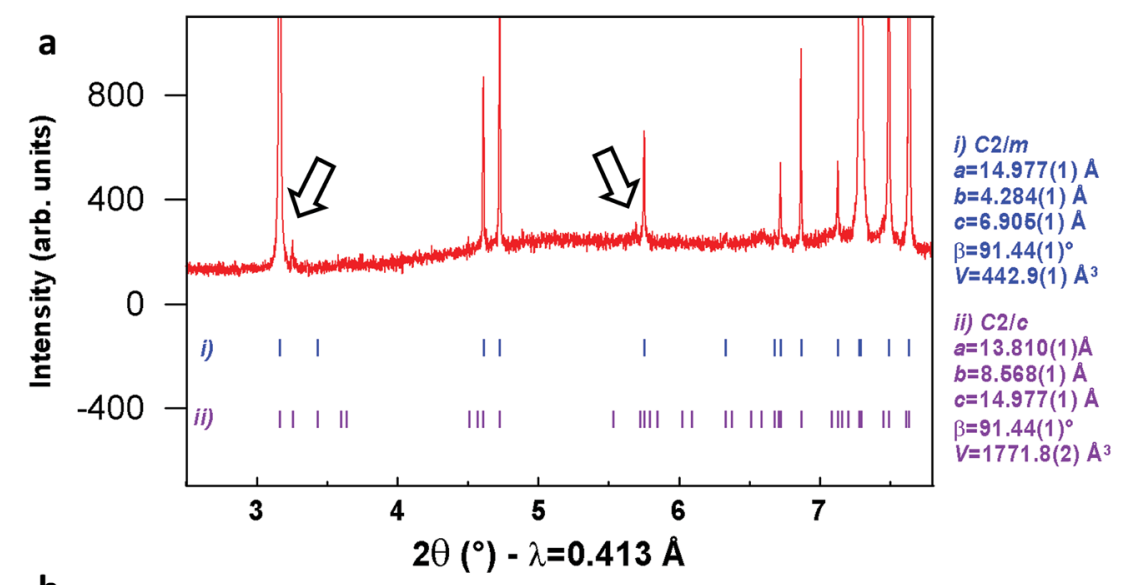

b

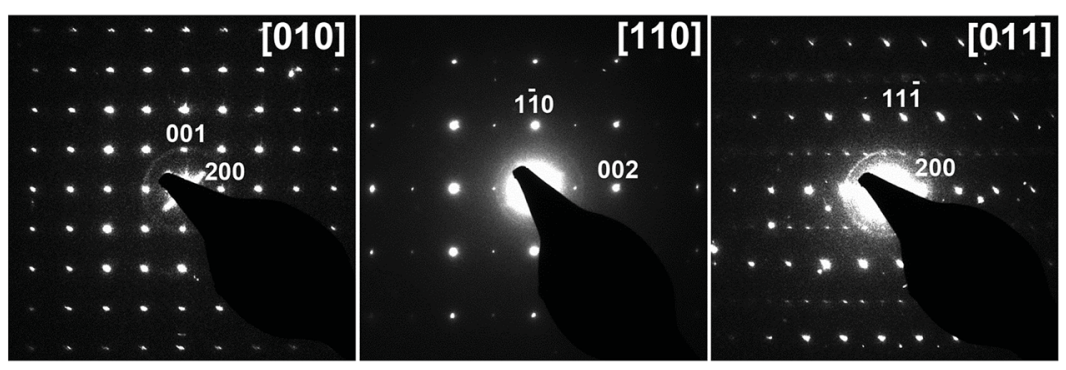

Fig. 1 (a) Portion of the synchrotron $\mathrm{X}$-ray powder pattern of $\mathrm{KFeSO}_{4} \mathrm{~F}$ indexed to two cells (i) and (ii), the latter being four times larger than the former (see text). The black arrows highlight the tiny peaks that can be indexed to the large cell only. (b) Electron diffraction patterns; weak $h, k / 2$, //2 reflections in the [011] ED pattern indicate that the quadruple unit cell should be used for solving the structure. 
solely obtain the $\mathrm{KFeSO}_{4} \mathrm{~F}$ monoclinic polymorph as a single phase, the reason why from now on we will discuss this phase, whose structure has been fully resolved by combined neutron and synchrotron diffraction and microscopy measurements as shown next.

\section{Structural characterization}

The structure of the low temperature $\mathrm{KFeSO}_{4} \mathrm{~F}$ polymorph was resolved by complementary synchrotron X-ray diffraction data $(\mathrm{XRD})$ at $300 \mathrm{~K}$ that was recorded in transmission mode $(\lambda=$ $0.4138 \AA$ ) at the 11-BM beam line at Argonne National Laboratory and neutron powder diffraction data $(\lambda=1.495 \AA$, high intensity mode, $300 \mathrm{~K}$ ) measured with an HRPT neutron diffractometer at SINQ-PSI (Villigen, Switzerland). All powder patterns were refined using the Rietveld method ${ }^{15}$ as implemented in the FullProf program. ${ }^{\mathbf{1 6 , 1 7}}$

The XRD pattern shown in Fig. 1a presents sharp peaks that can be indexed at first to a monoclinic C-centered unit cell with lattice parameters $a=14.977(1) \AA, b=4.284(1) \AA, c=6.905(1) \AA$ and $\beta=91.44(1)^{\circ}$. This cell, that can accommodate four $\mathrm{KFeSO}_{4} \mathrm{~F}$ formula units, has a volume of $442.9 \AA^{3}$. As no structural analog was known, we used both $a b$ initio structural determination with $\mathrm{SO}_{4}$ described as rigid tetrahedral groups with the FOX program, and direct methods with the Expo software, in the $C 2 / m$ space groups and in its subgroups $C 2$ and
$\mathrm{Cm}$, to fully resolve the structure. However, all obtained structural models presented either strongly distorted $\mathrm{FeO}_{4} \mathrm{~F}_{2}$ or unrealistic short $\mathrm{O}-\mathrm{O}$ distances $(1.5 \AA)$. When tested against the neutron powder diffraction pattern, they all showed a high discrepancy between the observed and the calculated pattern. Moreover, we noticed in the XRD pattern the presence of additional tiny peaks that could not be identified as impurities and could reveal a larger unit cell. TEM analysis was therefore carried out on a Tecnai G2 electron microscope operating at 200 $\mathrm{kV}$. To do so, the sample was prepared in an Ar-filled glovebox by crushing the grainy powder in a mortar in anhydrous hexane and depositing drops of the suspension onto holey carbon grids. The sample was transported to the microscope column completely excluding contact with air. Electron diffraction patterns of $\mathrm{KFeSO}_{4} \mathrm{~F}$ are shown in Fig. 1b. All bright reflections can be indexed to the monoclinic unit cell with $a \sim 15 \AA, b \sim 4.3$ $\AA$, and $c \sim 6.9 \AA$, with the only $h k l: h+k=2 n$ reflection condition suggesting the C-centered unit cell, in agreement with XRD. However, we can also notice weak $h, k / 2, l / 2$ reflections in the [011] ED pattern, which formally require a unit cell with doubled $b$ and $c$ parameters.

This four-times-larger unit cell that now accommodates 16 $\mathrm{KFeSO}_{4} \mathrm{~F}$ formula units turns out to perfectly index the tiny peaks visible in the X-ray diffraction pattern (Fig. 1a). The structure was then solved in the $C 2 / c$ (the $a$ and $c$ axes were switched to maintain the standard space group setting) space
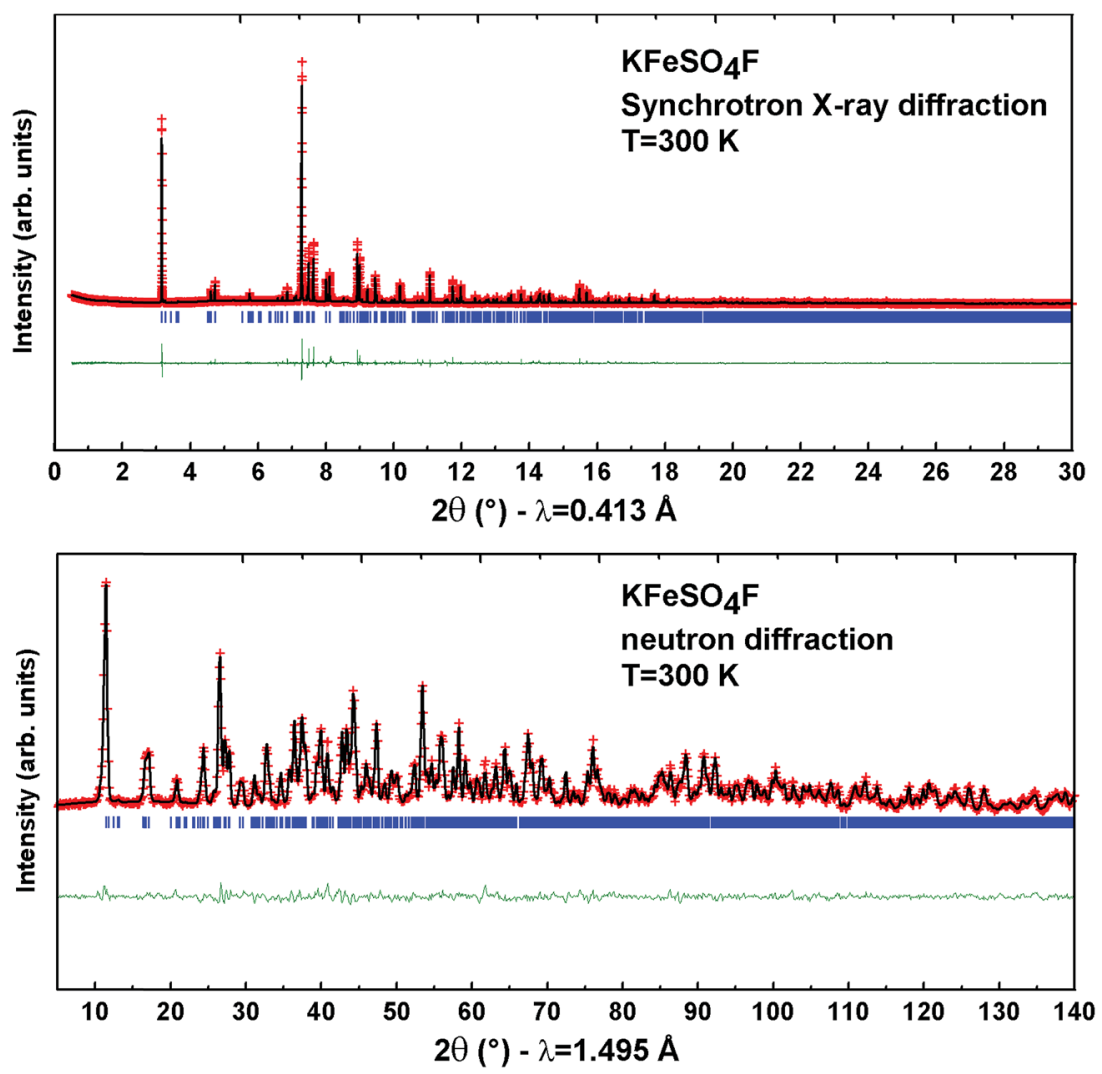

Fig. 2 Rietveld refinement of synchrotron (top) and neutron (bottom) diffraction patterns of $\mathrm{KFeSO}_{4} \mathrm{~F}(T=300 \mathrm{~K})$. The red crosses, black continuous line and bottom green line represent the observed, calculated and difference patterns, respectively. Vertical blue tick bars mark the reflection positions. 
group with lattice parameters $a=13.81021(3) \AA, \quad b=$ 8.568480(17) $\AA$, $c=14.97753(4) \AA$ and $\beta=91.43387(15)^{\circ}(V=$ $1771.774(7) \AA^{3}$ ). Iron and potassium positions were found by direct methods on the synchrotron X-ray diffraction pattern, while $\mathrm{SO}_{4}$ groups were obtained from the neutron powder pattern using $a b$ initio determination. Final refinements on neutron and synchrotron diffraction patterns were made with all atoms freely refined. The residual profiles are shown in Fig. 2.

Table 1 gives the refined atomic positions and structural parameters deduced from the combined refinement of the neutron and synchrotron data. There are 18 independent atomic positions; all of them in general are Wyckoff positions in

Table 1 Structural parameters of $\mathrm{KFeSO}_{4} \mathrm{~F}$ deduced from the combined Rietveld refinement of the neutron and synchrotron $\mathrm{X}$-ray diffraction patterns at $300 \mathrm{~K}^{a}$

\begin{tabular}{|c|c|c|c|c|c|}
\hline \multicolumn{6}{|c|}{ Space group $C 2 / c$} \\
\hline \multicolumn{6}{|c|}{$\begin{array}{l}a=13.81021(3) \AA, b=8.568480(17) \AA, c=14.97753(4) \AA \text { and } \\
\beta=91.43387(15)^{\circ}\end{array}$} \\
\hline \multicolumn{6}{|c|}{$V=1771.774(7) \AA^{3} z=16$} \\
\hline Atom & $\begin{array}{l}\text { Wyckoff } \\
\text { site }\end{array}$ & $x$ & $y$ & $z$ & $B\left(\AA^{2}\right)$ \\
\hline K1 & $8 f$ & $0.1295(11)$ & $0.366(3)$ & $0.4449(10)$ & $2.2(3)$ \\
\hline K2 & $8 f$ & $0.3745(10)$ & $0.377(3)$ & $0.0787(10)$ & $1.8(2)$ \\
\hline $\mathrm{Fe} 1$ & $8 f$ & $0.2507(5)$ & $0.1331(12)$ & $0.2508(4)$ & $0.66(8)$ \\
\hline $\mathrm{Fe} 2$ & $4 \mathrm{e}$ & 0 & $0.1694(8)$ & $1 / 4$ & $0.64(15)$ \\
\hline $\mathrm{Fe} 3$ & $4 e$ & 0 & $0.5823(12)$ & $1 / 4$ & $1.70(20)$ \\
\hline F1 & $8 f$ & $0.1313(8)$ & $0.1574(12)$ & $0.3176(7)$ & $1.3(2)$ \\
\hline F2 & $8 f$ & $0.3730(9)$ & $0.0866(13)$ & $0.1870(7)$ & $1.8(2)$ \\
\hline S1 & $8 f$ & $0.1333(11)$ & $0.372(3)$ & $0.1157(10)$ & $0.8(2)$ \\
\hline O1 & $8 f$ & $0.1968(11)$ & $0.2354(16)$ & $0.1344(9)$ & $2.5(3)$ \\
\hline $\mathrm{O} 2$ & $8 f$ & $0.3027(9)$ & $0.0168(13)$ & $0.3744(8)$ & $1.7(2)$ \\
\hline $\mathrm{O} 3$ & $8 f$ & $0.0969(7)$ & $0.3643(17)$ & $0.0256(6)$ & $1.93(16)$ \\
\hline $\mathrm{O} 4$ & $8 f$ & $0.0555(5)$ & $0.3727(15)$ & $0.1808(5)$ & $1.11(12)$ \\
\hline S2 & $8 f$ & $0.3938(12)$ & $0.374(3)$ & $0.3548(10)$ & $1.0(2)$ \\
\hline O5 & $8 f$ & $0.0452(10)$ & $0.0144(14)$ & $0.1496(9)$ & $1.8(2)$ \\
\hline O6 & $8 f$ & $0.5494(11)$ & $0.2388(16)$ & $0.1534(9)$ & $2.1(2)$ \\
\hline O7 & $8 f$ & $0.1541(7)$ & $0.1219(18)$ & $0.5542(6)$ & $2.33(17)$ \\
\hline O8 & $8 f$ & $0.3147(6)$ & $0.3785(19)$ & $0.2859(6)$ & $1.69(16)$ \\
\hline
\end{tabular}

${ }^{a}$ Reliability parameters: Bragg R-factor $=3.28 \%$; Rf-factor $=1.54 \%$.
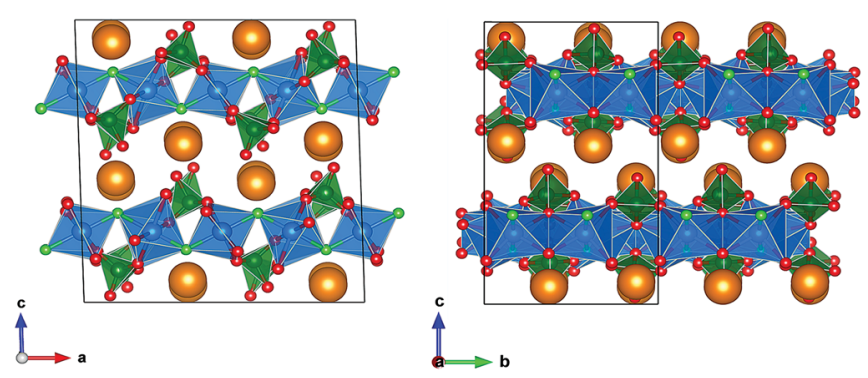

Fig. 3 Structure of $\mathrm{KFeSO}_{4} \mathrm{~F}$ seen along the [010] and [100] directions. $\mathrm{K}$ is orange, $\mathrm{Fe}$ is blue, $\mathrm{F}$ is green, and $\mathrm{O}$ is red. $\mathrm{SO}_{4}$ tetrahedral groups are coloured dark green. 8f except two of the three iron positions which sit in $4 \mathrm{e}$. There are two independent $\mathrm{K}$ and two independent $\mathrm{F}$ positions.

The structure of $\mathrm{KFeSO}_{4} \mathrm{~F}$ is shown in Fig. 3. It is a layer-type structure, with " $\mathrm{FeSO}_{4} \mathrm{~F}$ " layers stacked along [001], and potassium atoms located between them. Each layer is made of cornerand edge-shared $\mathrm{FeO}_{4} \mathrm{~F}_{2}$ distorted octahedra, also linked to each other through $\mathrm{SO}_{4}$ tetrahedral groups. Fig. 4 presents a view of a single layer, together with the local coordination of the iron
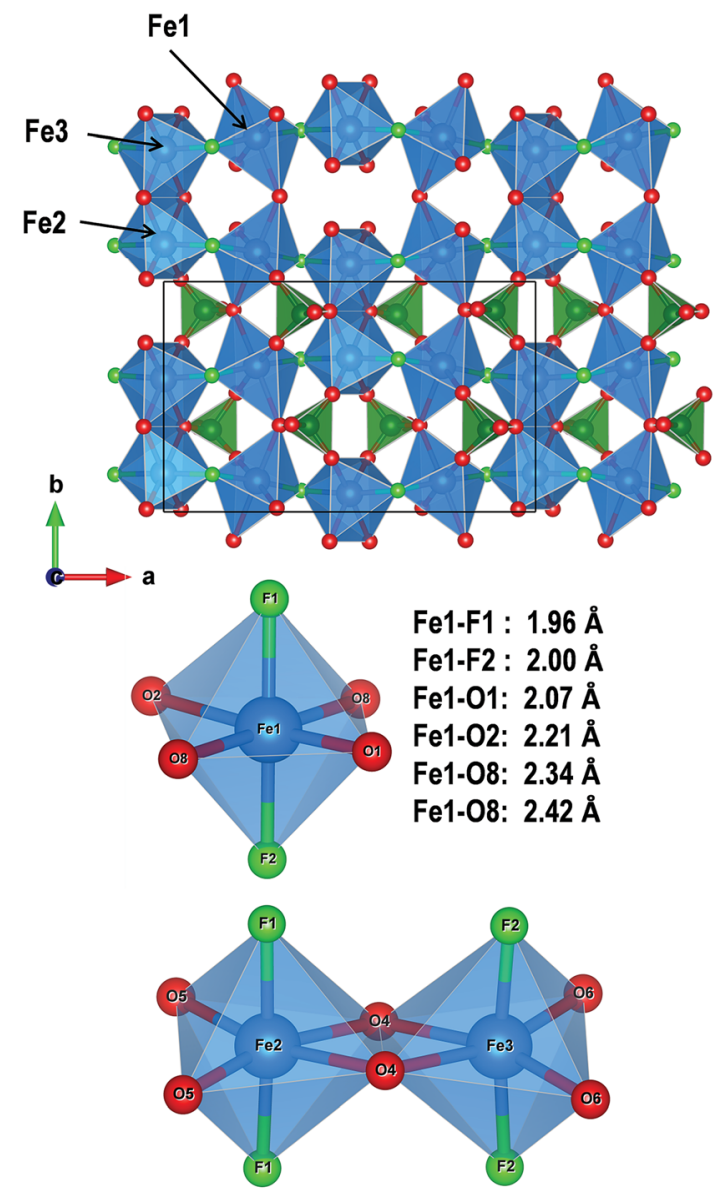

$\begin{array}{ll}\text { Fe2-F1: } 2.06 \AA(x 2) & \text { Fe3-F2 : } 1.97 \AA(x 2) \\ \text { Fe2-04: } 2.18 \AA(x 2) & \text { Fe3-O4: } 2.22 \AA(x 2) \\ \text { Fe2-05: } 2.11 \AA(x 2) & \text { Fe3-O6: } 2.10 \AA(x 2)\end{array}$

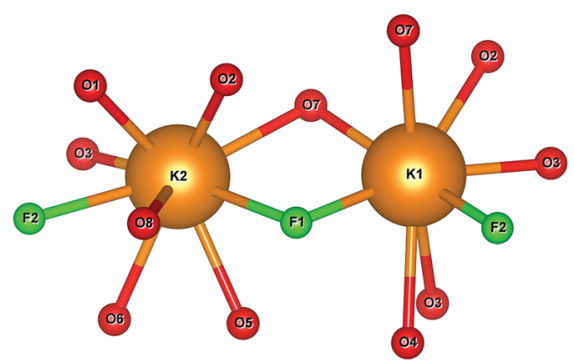

Fig. 4 Top: view of a single layer made of $\mathrm{FeO}_{4} \mathrm{~F}_{2}$ octahedra linked either via edges or vertices, and connected to each other through $\mathrm{SO}_{4}$ groups. $\mathrm{SO}_{4}$ tetrahedra were removed in the upper part of the view for clarity in highlighting the connection between Fe. Bottom: local coordination of iron and potassium atoms. 
atoms. The three $\mathrm{Fe} 1, \mathrm{Fe} 2$ and $\mathrm{Fe} 3$ sites have fluorine atoms in trans configuration, with the Fe-F distances smaller than the $\mathrm{Fe}-\mathrm{O}$ ones. Fe1 sits in the middle of an elongated octahedron; it is linked to another $\mathrm{Fe}_{1} \mathrm{O}_{4} \mathrm{~F}_{2}$ octahedron through $\mathrm{O} 8$ and to $\mathrm{Fe} 2$ and $\mathrm{Fe} 3$ via its two fluorine ligands, through vertices only. $\mathrm{Fe} 2$ and $\mathrm{Fe} 3$ are also in octahedral coordination; however, these two octahedra share an $\mathrm{O} 4-\mathrm{O} 4$ edge. In addition to this edge- and corner-sharing, octahedra are linked through $\mathrm{SO}_{4}$ groups. The $\mathrm{K}$ atoms that are located between the layers in the $\mathrm{K} 1$ and $\mathrm{K} 2$ positions are eight-fold and nine-fold coordinated, respectively, both with two $\mathrm{F}$ atoms and oxygen atoms at distances ranging between 2.6 and $3.2 \AA$.

Furthermore, a ${ }^{57} \mathrm{Fe}$ Mössbauer spectrum was recorded in transmission geometry in constant acceleration mode and with a ${ }^{57} \mathrm{Co}(\mathrm{Rh})$ source with a nominal activity of $925 \mathrm{MBq}$. The velocity scale $\left( \pm 4 \mathrm{~mm} \mathrm{~s}^{-1}\right)$ was calibrated at room temperature with an $\alpha$-Fe foil standard. The absorber was prepared from 10 $\mathrm{mg} \mathrm{cm}^{-2}$ of powder sample mixed with the boron nitride binder. The hyperfine parameters were fitted with Lorentzian lines. The spectrum (Fig. 5) fully confirms the structure since it is typical for $\mathrm{Fe}^{2+}$. It can be fitted using three doublets with similar isomer shifts of $1.28,1.29$ and $1.28 \mathrm{~mm} \mathrm{~s}^{-1}$, respectively. Their relative absorption area ratio of approximately $50: 25: 25$ is in perfect agreement with the multiplicity of the three crystallographic Wyckoff sites on which iron is distributed (Table 1). It is worth mentioning that the quadrupole splitting of the Fe1 site $\left(2.68 \mathrm{~mm} \mathrm{~s}^{-1}\right)$ is larger than the ones for the Fe2 and Fe3 sites (2.17 $\mathrm{mm} \mathrm{s}^{-1}$ and $2.55 \mathrm{~mm} \mathrm{~s}^{-1}$, respectively), which is consistent with the fact that the Fe1 atom sits in a more distorted octahedral environment than the ones around $\mathrm{Fe} 2$ and Fe3.

Finally, based on the $\mathrm{KFeSO}_{4} \mathrm{~F}$ solved structure, we could nicely fit the patterns collected for the $\mathrm{Cu}$ and $\mathrm{Mn}$ analogs and obtain with great accuracy the lattice parameters for these two compounds, despite the presence of impurities. As expected, the deduced unit cell volumes increase with increasing ionic radius of the respective $M^{+ \text {II }}$ cations but are systematically lower than those of the corresponding orthorhombic polymorphs (Fig. 6). This comes as no surprise as high temperature phases

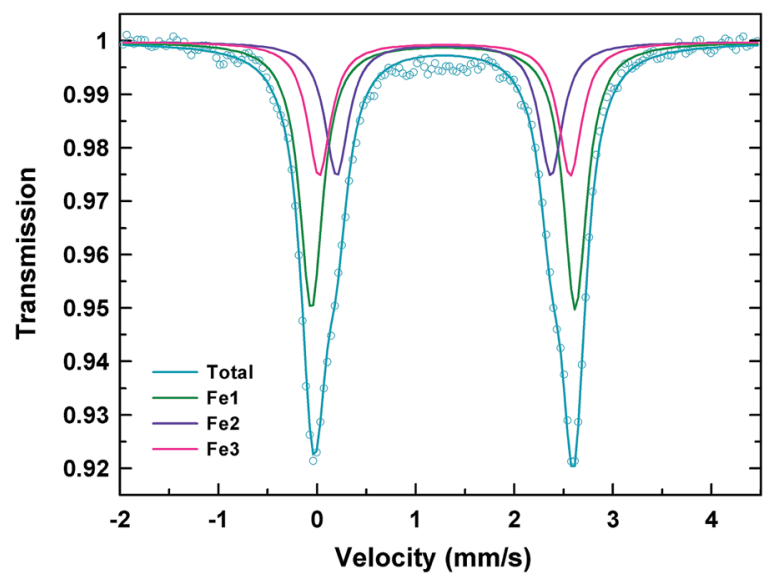

Fig. 5 Room temperature ${ }^{57} \mathrm{Fe}$ Mössbauer spectrum of monoclinic $\mathrm{KFeSO}_{4} \mathrm{~F}$ showing the three distinct $\mathrm{Fe}^{2+}$ sites.

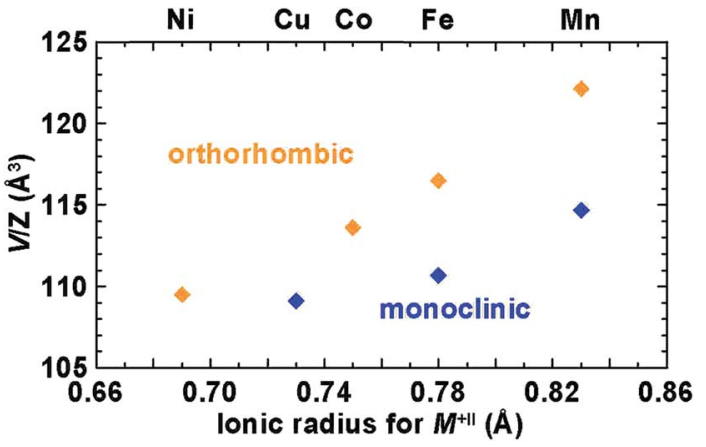

Fig. 6 Evolution of the volume per formula unit as a function of the ionic radii of the $3 \mathrm{~d}$ transition metal cations $\mathrm{M}^{+11}$ in the $\mathrm{KMSO}_{4} \mathrm{~F}$ series with $\mathrm{M}=\mathrm{Ni}, \mathrm{Cu}, \mathrm{Co}, \mathrm{Fe}, \mathrm{Mn}$. Blue and orange points represent the monoclinic and orthorhombic polymorphs, respectively.

(in this case the orthorhombic phase) tend to have a lower density.

\section{Polymorph stability}

The thermal evolution of monoclinic $\mathrm{KFeSO}_{4} \mathrm{~F}$ was explored through Differential Scanning Calorimetry (DSC) measurements (Fig. SI $1 \dagger$ blue line) coupled with thermogravimetric analysis measurements (TGA, green line) with a ramp of $1{ }^{\circ} \mathrm{C}$ $\min ^{-1}$ under argon. The DSC trace shows an endothermic peak at $380{ }^{\circ} \mathrm{C}$, with an enthalpy of approximately $4.35(5) \mathrm{kJ} \mathrm{mol}^{-1}$, which corresponds to the monoclinic to orthorhombic $\mathrm{KFeSO}_{4} \mathrm{~F}$ phase transition as confirmed by XRD. Note that the peak associated with this phase transition is better seen with a faster heating rate of $5{ }^{\circ} \mathrm{C} \mathrm{min}^{-1}$, with however a significant shift in temperature that is suggestive of a first order phase transition (Fig. 7). This phase transition is irreversible as deduced by the XRD powder pattern of a sample cooled down to room temperature that shows the orthorhombic structure. In the absence of structural similarity between the monoclinic and orthorhombic $\mathrm{KFeSO}_{4} \mathrm{~F}$ polymorphs, we believe that this phase transition is reconstructive rather than topotactic. Similarly, an irreversible monoclinic-orthorhombic phase transition was observed by ball-milling monoclinic $\mathrm{KFeSO}_{4} \mathrm{~F}$ for 15 min using a

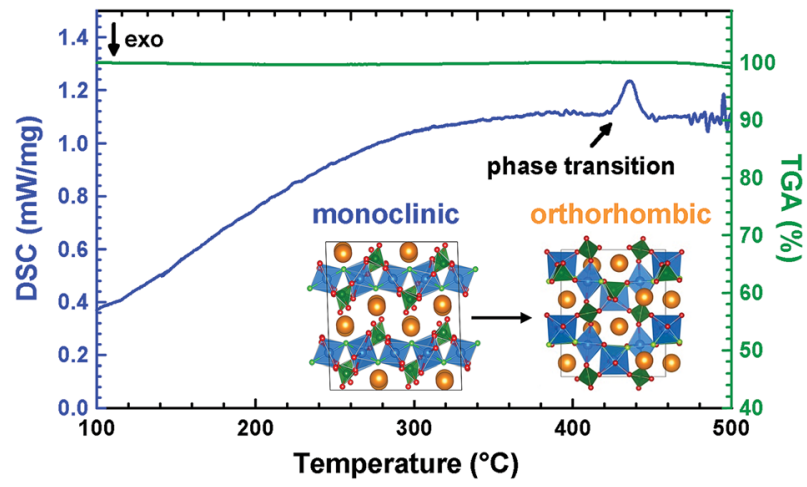

Fig. 7 DSC measurements (blue) of the monoclinic $\mathrm{KFeSO}_{4} \mathrm{~F}$ heated to $500{ }^{\circ} \mathrm{C}$ with a ramp of $5{ }^{\circ} \mathrm{C} \mathrm{min}^{-1}$ under an argon atmosphere. The green line corresponds to a coupled TGA measurement. 
Spex 8000 miller, even though the transition is not complete and competes with a global amorphisation process. Notice that the stabilization of the less dense orthorhombic $\mathrm{KFeSO}_{4} \mathrm{~F}$ polymorph from the denser monoclinic one $\left(2.99 \mathrm{~g} \mathrm{~cm}^{-3} v s\right.$. $3.15 \mathrm{~g} \mathrm{~cm}^{-3}$ ) by ball-milling is counterintuitive. It contrasts with previously observed trends for $\mathrm{LiFeSO}_{4} \mathrm{~F}, \mathrm{LiFeSO}_{4} \mathrm{OH}$ and $\mathrm{Li}_{2}$ $\mathrm{Fe}\left(\mathrm{SO}_{4}\right)_{2}$, where for each case the formation of the denser polymorph was favored by mechanical milling. ${ }^{5,9,13}$ We do not have any explanation with the exception that in this case, the local heating during the milling process might overrule the generated pressure and therefore promote the transition to the high temperature orthorhombic phase.

After having examined the thermal stability of this new monoclinic $\mathrm{KFeSO}_{4} \mathrm{~F}$ polymorph, we now want to further check its possible interesting electrochemical behavior.

\section{Electrochemistry}

Electrochemical tests were conducted in Swagelok-type cells assembled in an argon-filled glovebox and cycled in a galvanostatic operating mode using a VMP system (Biologic S.A., Claix, France). Lithium metal was used as the negative electrode and the working electrode consisted of a composite of the active material and carbon SP ( $80: 20 \mathrm{wt} \%)$, prepared by ball-milling for $15 \mathrm{~min}$ in a Spex 8000 miller. The negative and the positive electrodes were separated by using a Whatman GF/D borosilicate glass fiber sheet saturated with $1 \mathrm{M} \mathrm{LiPF}_{6}$ in EC: DMC (1: 1 weight ratio) (LP30). If not otherwise specified, cells were cycled at $\mathrm{C} / 50$ (1C means uptake or removal of $1 \mathrm{Li}^{+}$in $1 \mathrm{~h}$ ).

A typical voltage-composition curve obtained for the monoclinic $\mathrm{KFeSO}_{4} \mathrm{~F}$ is shown in Fig. 8a. Upon initial oxidation, two plateaus can be distinguished. The first one is situated around $3.8 \mathrm{~V} v s . \mathrm{Li}^{+} / \mathrm{Li}^{0}$ and accounts for $0.5 \mathrm{~K}^{+}$extracted. The second one $(4.4 \mathrm{~V})$, during which around $0.3 \mathrm{~K}^{+}$is removed, is rather sloppy and not well defined as can be also seen in the derivative curve $\mathrm{d} x / \mathrm{d} V$ (Fig. 8b). On discharge, $0.5 \mathrm{Li}^{+}$out of the 0.8 extracted $\mathrm{K}^{+}$can be re-inserted, which leads to a reversible capacity of $78 \mathrm{mAh} \mathrm{g}^{-1}$. The following cycles for the K-deficient electrode versus Li differ heavily from the initial oxidation and the voltage-composition trace exhibits an S-shaped curve around 3.6 V. The large polarization of the curve as compared to the orthorhombic phase (Fig. $8 \mathrm{c}$ and d) indicates sluggish kinetics, which is also reflected in the lower power rate capabilities (insets in Fig. 8a and c). This could be indicative of poor
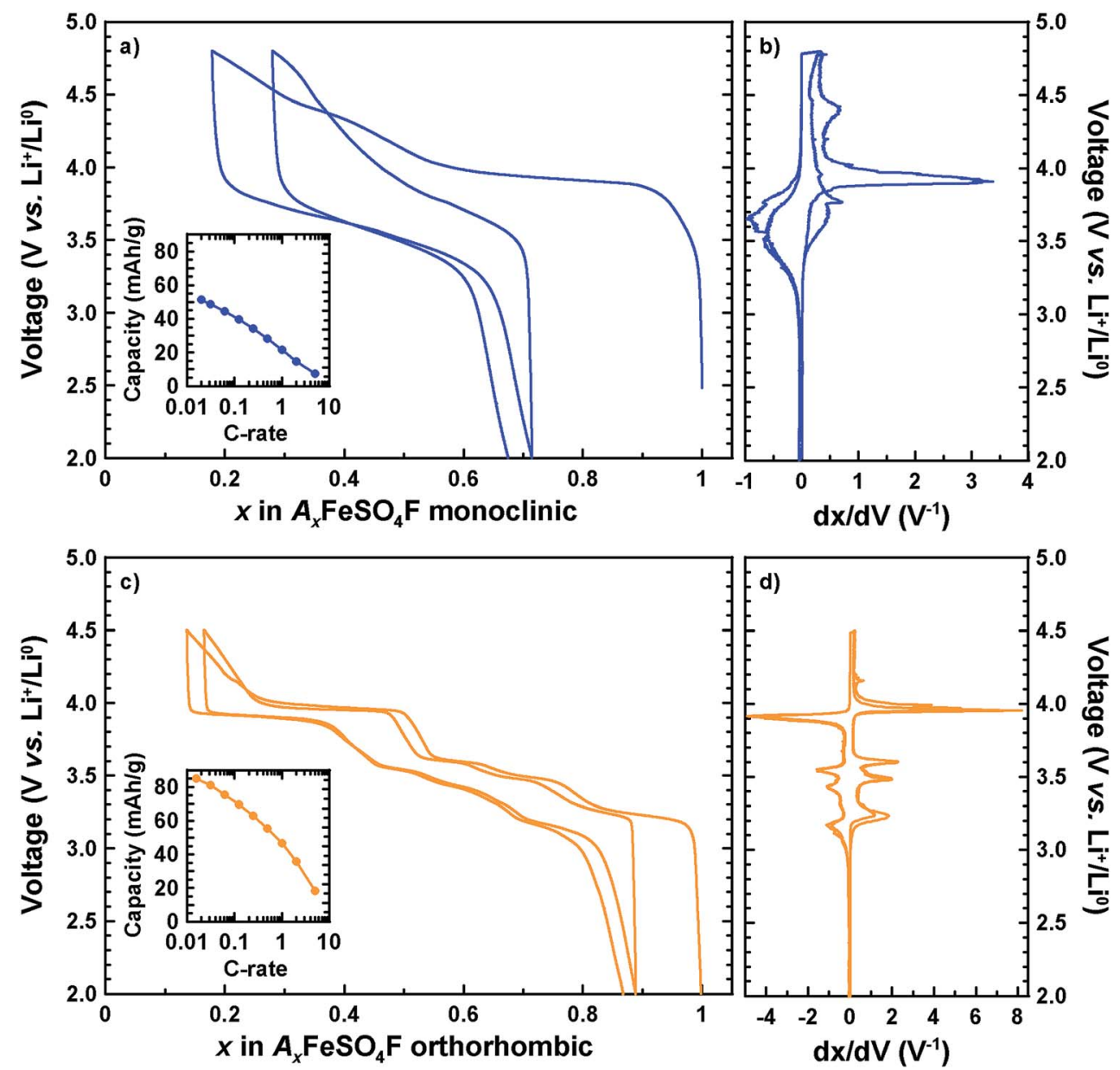

Fig. 8 The voltage-composition trace (a) and its derivative (b) of the monoclinic $\mathrm{KFeSO}_{4} \mathrm{~F}$ obtained upon heating at $265^{\circ} \mathrm{C}$ show two plateaus in the initial charge and an S-shaped curve upon following cycling. The high polarization as well as the low capacity upon faster $\mathrm{C}$-rates (power rate plot in the inset of (a)) indicate sluggish kinetics. For comparison, the voltage-composition trace (c) and its derivative (d) of orthorhombic $\mathrm{KFeSO}_{4} \mathrm{~F}$ as well as its power rate plot in the inset are shown. $A$ in $A \mathrm{FeSO}_{4} \mathrm{~F}$ corresponds to $\mathrm{K}$ in the first charge and $\mathrm{Li}$ onwards. 
ion diffusion in the monoclinic $\mathrm{KFeSO}_{4} \mathrm{~F}$ polymorph due to its higher density ( $3.15 \mathrm{~g} \mathrm{~cm}^{-3}$ ) as compared to the orthorhombic one $\left(2.99 \mathrm{~g} \mathrm{~cm}^{-3}\right)$. This is in agreement with what was observed in the cases of the tavorite/triplite $\mathrm{LiFeSO}_{4} \mathrm{~F}$ and layered/tavorite $\mathrm{LiFeSO}_{4} \mathrm{OH}$ phases, where the polymorph with the higher density also presented slower kinetics. ${ }^{\mathbf{8} 13}$ In contrast, denser polymorphs show higher redox potentials. Thus, the voltage necessary to fully oxidize $\mathrm{KFeSO}_{4} \mathrm{~F}$ may be higher than the stability limit of the electrolyte.

To grasp insights into the structural modifications associated with the removal of $\mathrm{K}^{+}$, in situ XRD electrochemical measurements were performed. The collected XRD patterns (ESI Fig. S2 $\dagger$ ) indicate a reversible two-phase insertion mechanism, but only limited structural information of the growing phase could be extracted due to the poor crystallinity of the cathode material once ball milled. To circumvent this issue, $\mathrm{K}_{x} \mathrm{FeSO}_{4} \mathrm{~F}$ samples with $x=0.5$ and $x=\sim 0.3$ were chemically prepared from $\mathrm{KFeSO}_{4} \mathrm{~F}$ using an oxidizing agent $0.5 \mathrm{~mol}$ or 1.2 mol equivalent of $\mathrm{NO}_{2} \mathrm{BF}_{4}$ in acetonitrile, respectively. The resulting XRD powder patterns (Fig. 9) show, aside from the

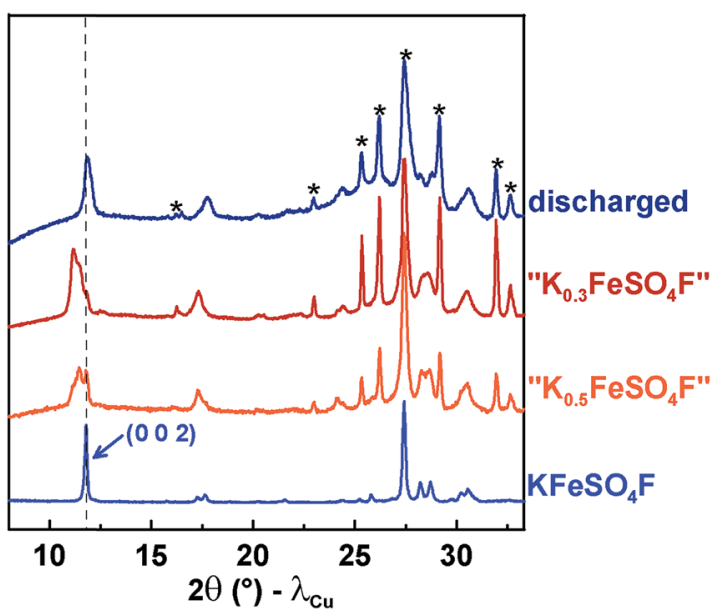

Fig. 9 XRD patterns of chemically oxidized samples of $\mathrm{K}_{x} \mathrm{FeSO}_{4} \mathrm{~F}$ with $x=0.5$ and $x=\sim 0.3$. The pristine phase $\mathrm{KFeSO}_{4} \mathrm{~F}$ is shown for comparison as well as the sample prepared by electrochemical reinsertion of lithium into the fully oxidized phase. The dashed line marks the position of the (002) peak of the pristine phase, which decreases at the expense of a new peak appearing during oxidation. * marks the peaks attributed to $\mathrm{KBF}_{4}$. main phase, the appearance of Bragg peaks corresponding to $\mathrm{KBF}_{4}$, which is indicative of the chemical removal of $\mathrm{K}^{+}$. However, this removal is not complete as a composition of $\sim \mathrm{K}_{0.3} \mathrm{FeSO}_{4} \mathrm{~F}$ was indirectly determined by Mössbauer measurements for samples treated with a large excess of $\mathrm{NO}_{2} \mathrm{BF}_{4}$ under reflux exceeding 3 days. Nevertheless, noticeable changes in the low angle region of the XRD pattern of the main phase can be observed, with namely the gradual appearance of a new broad peak at $2 \theta=11.3^{\circ}$ at the expense of the (002) peak of the pristine phase at $2 \theta=11.8^{\circ}$. This new peak can be indexed to the following parameters $a=13.52(2) \AA, b=8.32(4) \AA, c=$ 15.5(5) $\AA$ and $\beta=88.75(3)^{\circ}$. These variations are in agreement with what is expected for materials with a layered structure. The increase of $c$ by $0.67 \AA$ is indicative of an increase of the electronic repulsion between the negatively charged " $\mathrm{FeSO}_{4} \mathrm{~F}$ " layers upon the removal of the screening $\mathrm{K}^{+}$ions. In contrast, the shrinkage of $a$ and $b$ in-plane distances is associated with the reduction in size of $\mathrm{Fe}^{2+}$ when oxidized to $\mathrm{Fe}^{3+}$ during $\mathrm{K}^{+}$ extraction. The reverse peak amplitude variation and peak shift observed upon electrochemical reinsertion of $\mathrm{Li}^{+}$confirm the reversibility of the process. The lower $c$ parameter for the relithiated vs. the pristine $\mathrm{KFeSO}_{4} \mathrm{~F}$ phase $(14.85 \AA$ vs. $14.97 \AA)$ is simply due to the smaller size of $\mathrm{Li}^{+}$as compared to $\mathrm{K}^{+}(0.69 \AA$ vs. $1.21 \AA$ ).

Overall, the difficulties encountered both electrochemically and chemically for the removal of $\mathrm{K}^{+}$from monoclinic $\mathrm{KFeSO}_{4} \mathrm{~F}$ as compared to orthorhombic $\mathrm{KFeSO}_{4} \mathrm{~F}$ are most likely indicative of differences in terms of the $\mathrm{K}^{+}$diffusion pathways and therefore ionic conductivity in both polymorphs. This prompted us to explore in more detail the conductivity properties of the monoclinic and orthorhombic $\mathrm{KFeSO}_{4} \mathrm{~F}$ polymorphs.

\section{Conductivity}

Firstly, the Bond Valence Energy Landscape (BVEL) approach was used to sense differences in terms of the diffusion pathways of the potassium cations between the monoclinic and orthorhombic $\mathrm{KFeSO}_{4} \mathrm{~F}$ polymorphs. Within this approach bond valence energy landscapes were generated, where valence units are transformed into energy units as implemented in the program BondSTR of the Fullprof Suite. ${ }^{\mathbf{1 6}}$ For the calculation of BVEL, soft bond valence parameters developed by S. Adams ${ }^{\mathbf{1 8}}$ are used. They take into account the polarizability of the mobile a) Monoclinic: $E_{a}=2.83 \mathrm{eV}$

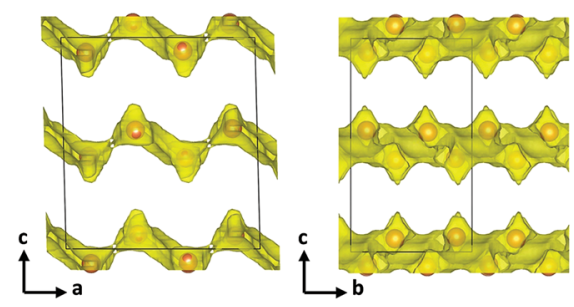

b) Orthorhombic: $E_{a}=0.40 \mathrm{eV}$

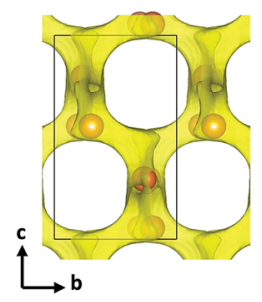

Fig. 10 Bond valence energy landscape (BVEL) of (a) monoclinic and (b) orthorhombic $\mathrm{KFeSO}_{4} \mathrm{~F}$. The energy values chosen for the plots lay 0.2 $\mathrm{eV}$ and $0.96 \mathrm{eV}$ above the activation energies of the monoclinic and orthorhombic polymorphs, respectively. The BVEL reveals that monoclinic $\mathrm{KFeSO}_{4} \mathrm{~F}$ is a $2 \mathrm{D}$ conductor, whereas the orthorhombic phase is a 3D conductor. 
species, in this case $\mathrm{K}^{+}$, and the influence of the counterions of the structure up to a distance of $8 \AA$. This approach allows visualizing conduction pathways in the structure while giving hints to possible conduction mechanisms. Fig. 10 shows the calculated BVEL for $\mathrm{K}^{+}$conduction pathways in the two $\mathrm{KFeSO}_{4} \mathrm{~F}$ polymorphs. These calculations reveal that activation energies of $2.83 \mathrm{eV}$ and $0.40 \mathrm{eV}$ for the monoclinic and orthorhombic phases are necessary to get an infinitely connected network in at least one dimension. This indirectly translates into the expectation of a much higher conductivity for the orthorhombic than for the monoclinic $\mathrm{KFeSO}_{4} \mathrm{~F}$ polymorph as anticipated. Moreover, the monoclinic phase presents $2 \mathrm{D}$ conduction pathways along the [100] and [010] directions (Fig. 10a), whereas the orthorhombic structure generates a 3D conduction pathway (Fig. 10b).

The differences in the conduction pathways seen by BVEL were an impetus to further explore the conduction properties by performing a.c. conductivity measurements using a BioLogic
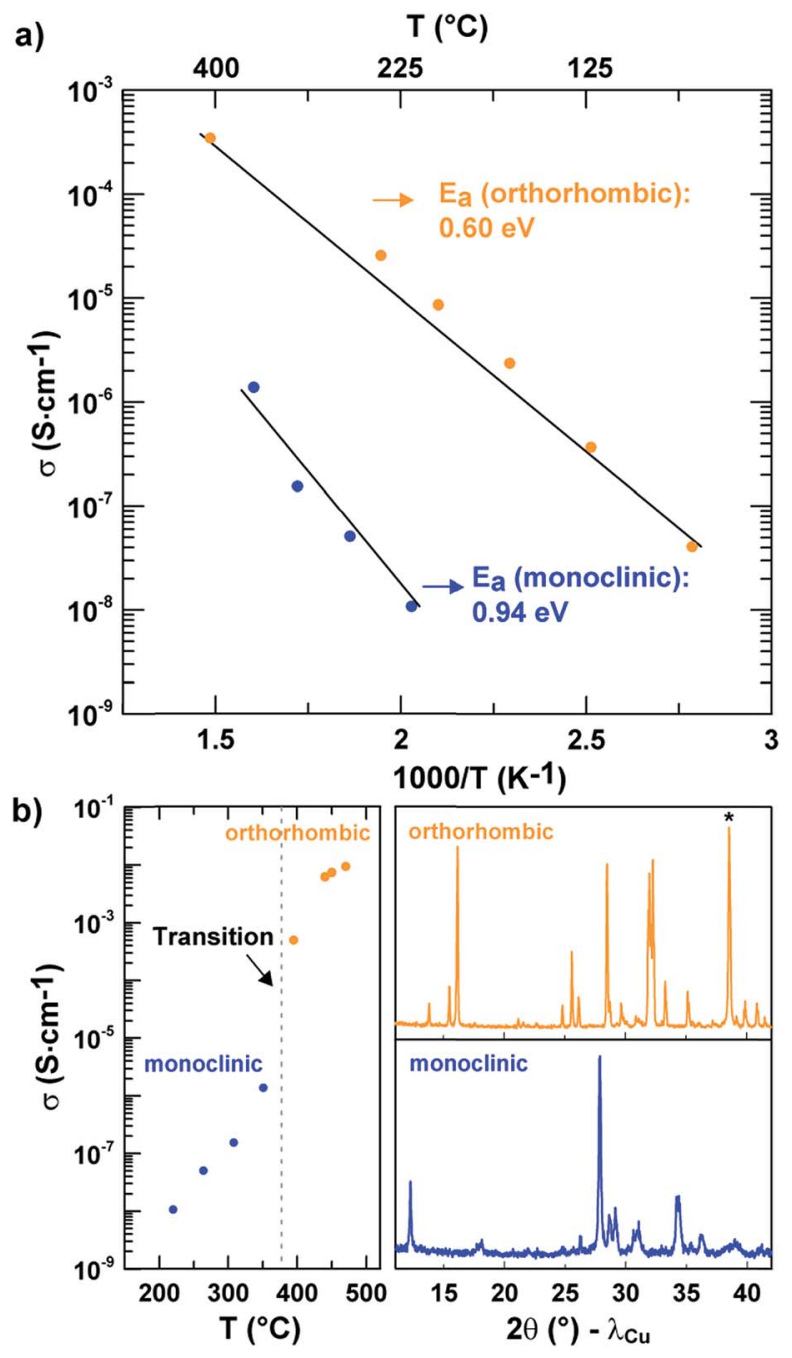

Fig. 11 (a) Temperature dependence of the a.c. conductivity of the orthorhombic (orange) and monoclinic (blue) $\mathrm{KFeSO}_{4} \mathrm{~F}$ polymorphs. (b) Monoclinic-orthorhombic phase transition measured by a.c. conductivity with their respective XRD patterns. $\left({ }^{*}\right)$ marks a peak due to the gold sputter.
MTZ-35 setup with platinum electrodes equipped with an HTF1100 furnace. Sintered pellets $(10 \mathrm{~mm}$ diameter, relative densities of $\sim 70 \%$, sputtered with gold) of the monoclinic and orthorhombic $\mathrm{KFeSO}_{4} \mathrm{~F}$ were measured from $35 \mathrm{MHz}$ to $1 \mathrm{~Hz}$ in the temperature range of $50{ }^{\circ} \mathrm{C}$ to $450{ }^{\circ} \mathrm{C}$ under argon flow. Fig. 11 shows the evolution of the a.c. conductivity with increasing temperature for the two polymorphs, where the orthorhombic phase (orange curve) shows an a.c. conductivity, which is three orders of magnitude higher than that of the monoclinic phase (blue curve). The experimental data were fitted using the Arrhenius equation $\sigma(T)=\sigma_{0} \exp \left(-E_{\mathrm{a}} / k_{\mathrm{B}} T\right)$,

a)

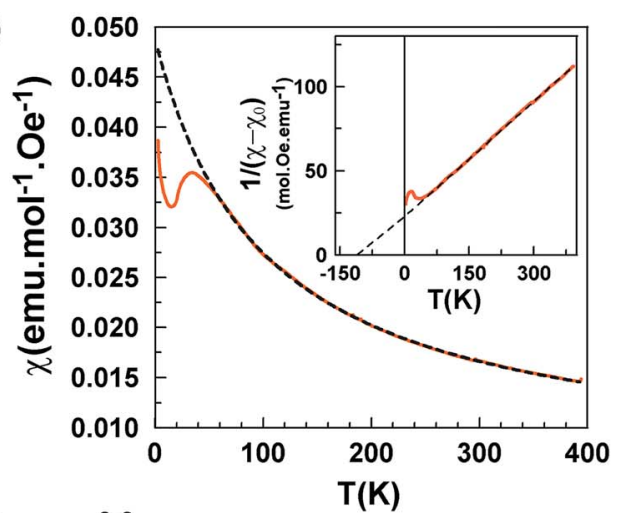

b)

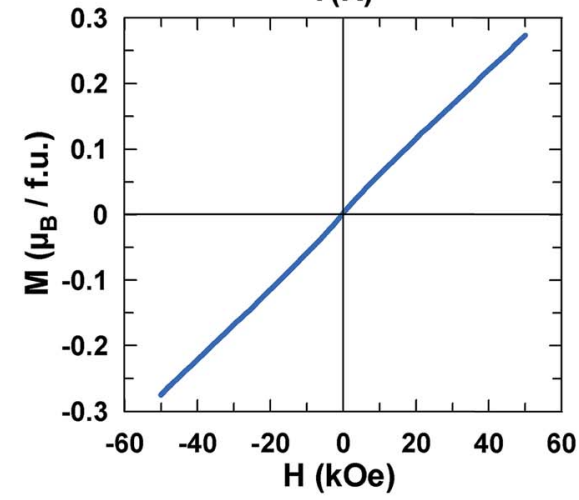

c)

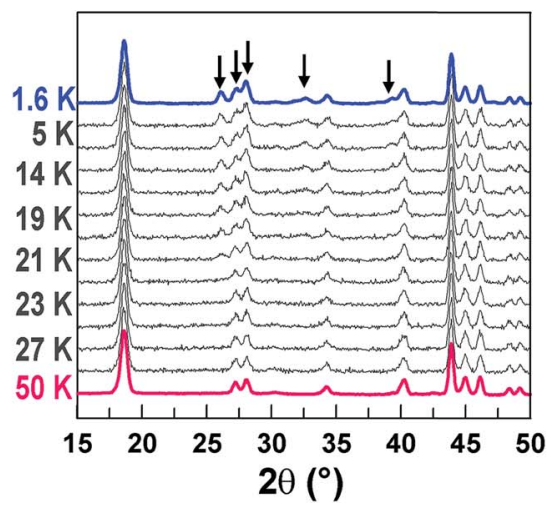

Fig. 12 (a) Temperature dependence of the magnetic susceptibility $(\chi)$ of $\mathrm{KFeSO}_{4} \mathrm{~F}$, measured under field-cooling conditions with a field of 1 $\mathrm{kOe}$ between $400 \mathrm{~K}$ and $2 \mathrm{~K}$. The fit of the Curie-Weiss law is indicated by the black dotted line. The inset shows the inverse magnetic susceptibility $\left(1 /\left(\chi-\chi_{0}\right)\right)$ as a function of temperature as well as the Curie-Weiss fit. (b) $\mathrm{KFeSO}_{4} \mathrm{~F}$ magnetization curve as a function of the applied field measured at $2 \mathrm{~K}$. (c) Evolution of the neutron powder patterns of $\mathrm{KFeSO}_{4} \mathrm{~F}$ between $1.6 \mathrm{~K}$ and $50 \mathrm{~K}$. The arrows mark the appearance of the magnetic peaks below $22 \mathrm{~K}$. 
where $\sigma$ is the conductivity at temperature $T, \sigma_{0}$ is the preexponential factor, $E_{\mathrm{a}}$ is the apparent activation energy for $\mathrm{K}^{+}$ migration, and $k_{\mathrm{B}}$ is the Boltzmann constant. Activation energies of $0.94 \mathrm{eV}$ for the monoclinic $\mathrm{KFeSO}_{4} \mathrm{~F}$ and of $0.60 \mathrm{eV}$ for its orthorhombic counterpart were obtained and room temperature a.c. conductivities of $8 \times 10^{-14} \mathrm{~S} \mathrm{~cm}^{-1}$ for the former and $8.5 \times 10^{-8} \mathrm{~S} \mathrm{~cm}^{-1}$ for the latter were extrapolated. Note that the monoclinic to orthorhombic phase transition already observed by DSC measurements (Fig. 7) can also be seen in the conductivity measurements at $390^{\circ} \mathrm{C}$, marked by an abrupt increase of the conductivity by three orders of magnitude (inset in Fig. 11). These experimental a.c. conductivity results are therefore in good agreement with the BVEL predictions.

\section{Magnetic properties}

Besides the electrochemical and conductivity performances of this new monoclinic $\mathrm{KFeSO}_{4} \mathrm{~F}$ polymorph, it was also studied for its physical properties. We shall remind that the high temperature KTP-like form of $\mathrm{KFeSO}_{4} \mathrm{~F}$ presents a non-centrosymmetric space group (Pna $\left.{ }_{1}\right)^{11}$ and therefore could be promising for non-linear optical properties. Even though the low temperature monoclinic phase reported here does not present a polar structure, and therefore cannot generate second harmonics effects, it may present other appealing physical features worth exploring. This prompted us to check on its magnetic characteristics. The temperature dependence of magnetization was measured using a SQUID (XL, Quantum Design), under both ZFC and FC conditions under 1 kOe between $2 \mathrm{~K}$ and $400 \mathrm{~K}$. The magnetic susceptibility $\chi$ of $\mathrm{KFeSO}_{4} \mathrm{~F}$ (Fig. 12a) shows clearly a cusp of long-range antiferromagnetic ordering occurring at the Néel temperature $\left(T_{\mathrm{N}}\right)$ of $\sim 25(3) \mathrm{K}$. The high-temperature region (50-400 K) of the susceptibility was fitted to the modified Curie-Weiss equation $\chi$ $=C /\left(T-\theta_{\mathrm{CW}}\right)+\chi_{0}$, which includes a temperature independent term to account for a diamagnetic contribution. An effective magnetic moment of $5.91 \mu_{\mathrm{B}}$ per Fe and $\theta_{\mathrm{CW}}=-101 \mathrm{~K}$ are deduced. The effective moment is in the range expected for a high spin $\mathrm{Fe}^{2+}$ ion $\left(5.48 \mu_{\mathrm{B}}\right)$ with an unquenched orbital moment that is fully decoupled from the spin contribution as calculated using the equation $\mu_{\mathrm{S}+\mathrm{L}}=(4 \mathrm{~S}(\mathrm{~S}+1)+\mathrm{L}(\mathrm{L}+1))^{1 / 2}$. The negative Curie-Weiss temperature indicates strong antiferromagnetic correlations, while the overall linear dependence of the magnetization on the applied field (Fig. 12b) indicates the absence of a ferromagnetic component.

To get more insight into the magnetic structure, high intensity neutron powder diffraction (D20, ILL) experiments were conducted at low temperature down to $1.6 \mathrm{~K}$. The pattern at $50 \mathrm{~K}$ (i.e. above the Néel temperature) is perfectly fitted using the structural model (space group $C 2 / c$ ) obtained at $300 \mathrm{~K}$, with however slightly smaller lattice parameters of $a=13.7867(3) \AA$, $b=8.54208(19) \AA, c=14.9299(4) \AA$ and $\beta=91.7503(17)^{\circ}(V=$ $1757.42(8) \AA^{3}$ ), as expected from thermal contraction (Fig. SI $3 \dagger$ ). This indicates the absence of a structural phase transition at low temperature. On further cooling, one can notice below 22(1) $\mathrm{K}$ the appearance of additional magnetic peaks (marked with arrows in Fig. 12c), which indicates the onset of a long-range ordering of the magnetic moments carried by $\mathrm{Fe}^{2+}$ atoms. This temperature is in perfect agreement with the Néel temperature $\left(T_{\mathrm{N}}=25(2) \mathrm{K}\right)$ deduced from the susceptibility measurements.

The magnetic reflections can be indexed to a propagation vector $\mathbf{k}=(1,0,0)$, so that the $\mathrm{C}$-centering of the lattice is

Table 2 The two possible magnetic structures for $\mathrm{KFeSO}_{4} \mathrm{~F}$, corresponding to the $\Gamma 3$ and $\Gamma 4$ representations deduced from the symmetry analysis (space group $C 2 / c$; propagation vector $\mathrm{k}=(1,0,0)$ ). Magnetic moments $(\mu \mathrm{B})$ at $1.6 \mathrm{~K}$, the components (in $\mu \mathrm{B}$ ) are given along the $a, b$, and $c$ axes $\left(M_{x}, M_{y}\right.$, and $\left.M_{z}\right)$ and spherical components $(M, \theta, \varphi)$ with respect to a Cartesian system in which $x$ is parallel to $a, y$ is in the $(a, b)$ plane and $z$ is along the $c$ plane*. Therefore, $\varphi=0$ corresponds to moments in the $(a, c)$ plane. Atoms whose label is preceded with a $C$ corresponding to those linked with the $(1 / 2,1 / 2,0)+$ lattice centering

\begin{tabular}{|c|c|c|c|c|c|c|c|}
\hline \multirow{2}{*}{$\begin{array}{l}\text { Refined } \\
\text { magnetic } \\
\text { moment }\end{array}$} & \multicolumn{4}{|c|}{ Coordinates $\left(\mu_{\mathrm{B}}\right)$ along the $a, b$, and $c$ axes } & \multicolumn{3}{|c|}{ Spherical coordinates } \\
\hline & $M_{x}=-1.15(9)$ & $M_{y}=0$ & $M_{z}=2.58(4)$ & & $M=2.85(3) \mu_{\mathrm{B}}$ & $\theta=-25(2)^{\circ}$ & $\varphi=0^{\circ}$ \\
\hline \multicolumn{8}{|c|}{ Representation $\Gamma_{3}$, Shubnikov group $C 2^{\prime} / c^{\prime}$} \\
\hline $\operatorname{Fe} 1(1)$ & $\mathrm{Fe} 1(2)$ & $\mathrm{Fe} 1(3)$ & $\mathrm{Fe} 1(4)$ & C-Fe1(1) & $\mathrm{C}-\mathrm{Fe} 1(2)$ & $\mathrm{C}-\mathrm{Fe} 1(3)$ & $\mathrm{C}-\mathrm{Fe} 1(4)$ \\
\hline$x, y, z$ & $\begin{array}{l}-x, y \\
-z+1 / 2\end{array}$ & $-x,-y,-z$ & $\begin{array}{l}x,-y \\
z+1 / 2\end{array}$ & $\begin{array}{l}x+1 / 2 \\
y+1 / 2, z\end{array}$ & $\begin{array}{l}-x+1 / 2 \\
y+1 / 2,-z+1 / 2\end{array}$ & $\begin{array}{l}-x+1 / 2 \\
-y+1 / 2,-z\end{array}$ & $\begin{array}{l}x+1 / 2,-y+1 / 2 \\
z+1 / 2\end{array}$ \\
\hline$+\mathrm{M}$ & $+\mathrm{M}$ & $+\mathrm{M}$ & $+\mathrm{M}$ & $-\mathrm{M}$ & $-\mathrm{M}$ & $-\mathrm{M}$ & $-\mathrm{M}$ \\
\hline $\mathrm{Fe} 2(1)$ & $\mathrm{Fe} 2(2)$ & C-Fe2(1) & C-Fe2(2) & Fe3(1) & Fe3(2) & C-Fe3(1) & C-Fe3(2) \\
\hline $0, y, 1 / 4$ & $0,-y, 1 / 4$ & $1 / 2, y+1 / 2,1 / 4$ & $\begin{array}{l}1 / 2,-y+1 / 2 \\
1 / 4\end{array}$ & $0, y, 1 / 4$ & $0,-y, 1 / 4$ & $1 / 2, y+1 / 2,1 / 4$ & $1 / 2,-y+1 / 2,1 / 4$ \\
\hline$+\mathrm{M}$ & $+\mathrm{M}$ & $-\mathrm{M}$ & $-\mathrm{M}$ & $-\mathrm{M}$ & $-\mathrm{M}$ & $+\mathrm{M}$ & $+\mathrm{M}$ \\
\hline \multicolumn{8}{|c|}{ Representation $\Gamma_{4}$, Shubnikov group $C 2^{\prime} / c$} \\
\hline $\operatorname{Fe} 1(1)$ & Fe1 $(2)$ & Fe1(3) & Fe1(4) & $\mathrm{C}-\mathrm{Fe} 1(1)$ & $\mathrm{C}-\mathrm{Fe} 1(2)$ & $\mathrm{C}-\mathrm{Fe} 1(3)$ & $\mathrm{C}-\mathrm{Fe} 1(4)$ \\
\hline$x, y, z$ & $\begin{array}{l}-x, y \\
-z+1 / 2\end{array}$ & $-x,-y,-z$ & $x,-y, z+1 / 2$ & $\begin{array}{l}x+1 / 2 \\
y+1 / 2, z\end{array}$ & $\begin{array}{l}-x+1 / 2 \\
y+1 / 2,-z+1 / 2\end{array}$ & $\begin{array}{l}-x+1 / 2 \\
-y+1 / 2,-z\end{array}$ & $\begin{array}{l}x+1 / 2,-y+1 / 2 \\
z+1 / 2\end{array}$ \\
\hline$+\mathrm{M}$ & $+\mathrm{M}$ & $-\mathrm{M}$ & $-\mathrm{M}$ & $-\mathrm{M}$ & $-\mathrm{M}$ & $+\mathrm{M}$ & $+\mathrm{M}$ \\
\hline $\mathrm{Fe} 2(1)$ & $\mathrm{Fe} 2(2)$ & $\mathrm{C}-\mathrm{Fe} 2(1)$ & $\mathrm{C}-\mathrm{Fe} 2(2)$ & $\mathrm{Fe} 3(1)$ & $\mathrm{Fe} 3(2)$ & $\mathrm{C}-\mathrm{Fe} 3(1)$ & $\mathrm{C}-\mathrm{Fe} 3(2)$ \\
\hline $0, y, 1 / 4$ & $0,-y, 1 / 4$ & $1 / 2, y+1 / 2,1 / 4$ & $\begin{array}{l}1 / 2,-y+1 / 2 \\
1 / 4\end{array}$ & $0, y, 1 / 4$ & $0,-y, 1 / 4$ & $1 / 2, y+1 / 2,1 / 4$ & $1 / 2,-y+1 / 2,1 / 4$ \\
\hline$+\mathrm{M}$ & $-\mathrm{M}$ & $-\mathrm{M}$ & $+\mathrm{M}$ & $-\mathrm{M}$ & $+\mathrm{M}$ & $+\mathrm{M}$ & $-\mathrm{M}$ \\
\hline
\end{tabular}


broken with the onset of magnetic order. The performed symmetry analysis for the three iron sites and its results (ESI Table S1 $\dagger$ ) are described in detail in the ESI $\dagger$ section. All the possibilities given by this symmetry analysis were tested against the neutron powder pattern recorded at $1.6 \mathrm{~K}$, with the following assumption: magnetic moments carried by the three iron crystallographic positions (i) follow the same representation $\Gamma_{i}(i=1,4)$ and (ii) have the same absolute value but may have different orientations. For implementing the second condition, a description of magnetic moments using spherical coordinates was chosen, with $\theta$ and $\varphi$ angles defined according to an orthogonal Cartesian system whose $x$ and $y$ axes coincide with the crystallographic $a$-axis and $b$-axis, respectively, and $z$ is perpendicular to the $x$ and $y$. We found that two magnetic structures, following the $\Gamma_{3}$ and $\Gamma_{4}$ representations with moments projected along basis vectors $\Psi_{1}$ and $\Psi_{3}$, may account for the observed neutron pattern at $1.6 \mathrm{~K}$. Moreover, as the refined $\theta$ and $\varphi$ values for $\mathrm{Fe} 1$ and $\varphi$ for $\mathrm{Fe} 2$ and $\mathrm{Fe} 3$ (symmetry analysis dictates a $\varphi=0^{\circ}$ angle for $\mathrm{Fe} 2$ and $\mathrm{Fe} 3$ ) led to (anti) parallel moments lying in the $(a, b)$ plane, the final refinements were done by constraining all magnetic moments to be of the same amplitude and collinearity (Table 2). The refined value of the magnetic moment is $M=2.85(3) \mu_{\mathrm{B}}$, a value slightly lower than what is expected for $\mathrm{Fe}^{2+}\left(\mathrm{d}^{6}, g S=4 \mu_{\mathrm{B}}\right)$. This may be due to the fact that the moments are not fully saturated as the compound presents relatively low Néel temperature $\left(T_{\mathrm{N}}=22 \mathrm{~K}\right)$. The two refinements in $\Gamma_{3}$ and $\Gamma_{4}$ are shown in Fig. 13a and b and the deduced magnetic structures in Fig. 13d and e. Fig. 13c illustrates the calculated magnetic contribution for each model compared to the difference between the patterns recorded at 1.6 $\mathrm{K}$ and $50 \mathrm{~K}$ that therefore contain only magnetic information. The two proposed models (corresponding to Shubnikov groups

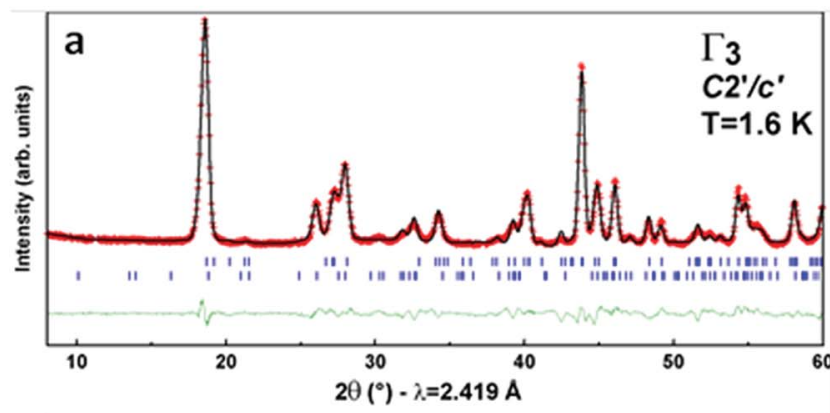

d
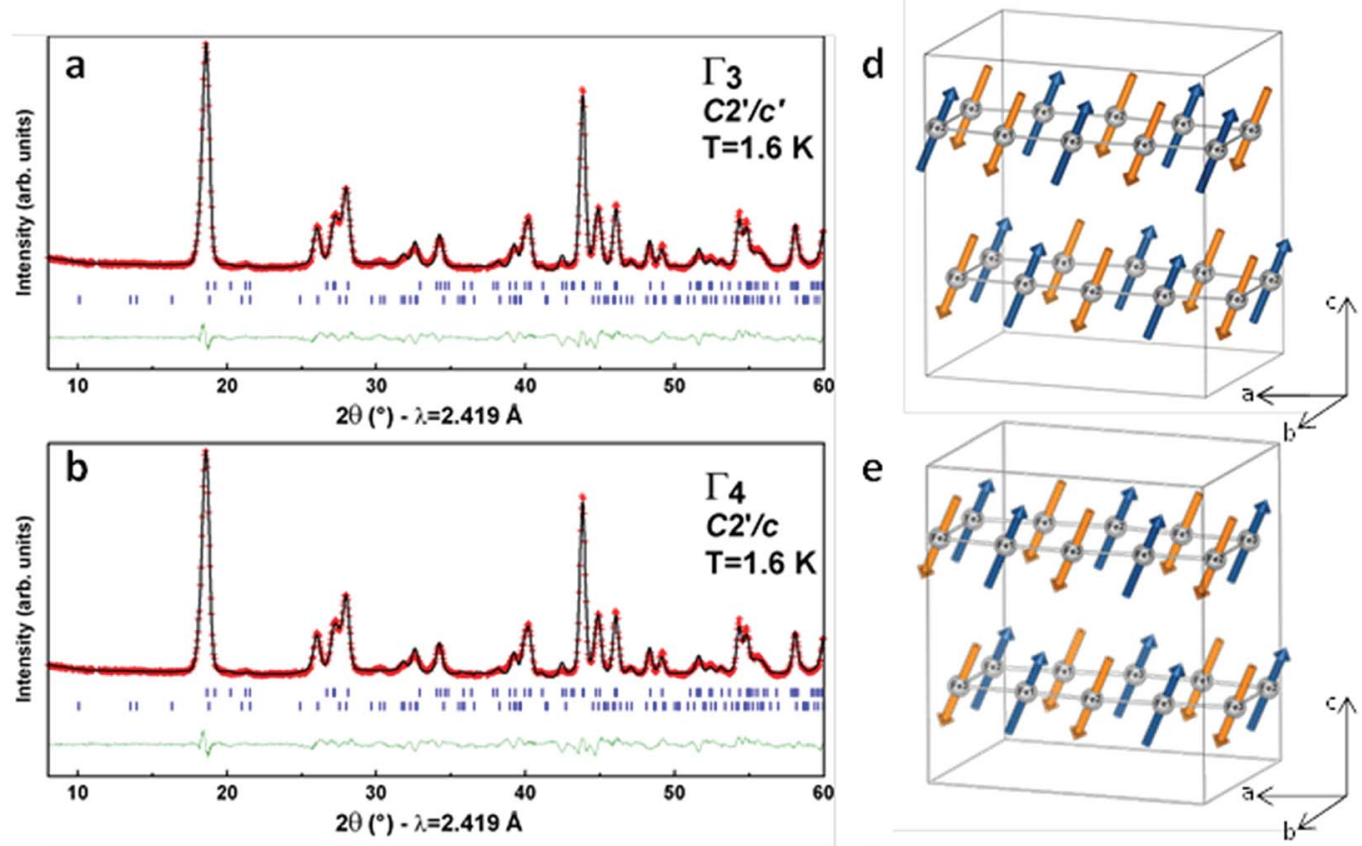

$\mathrm{e}$
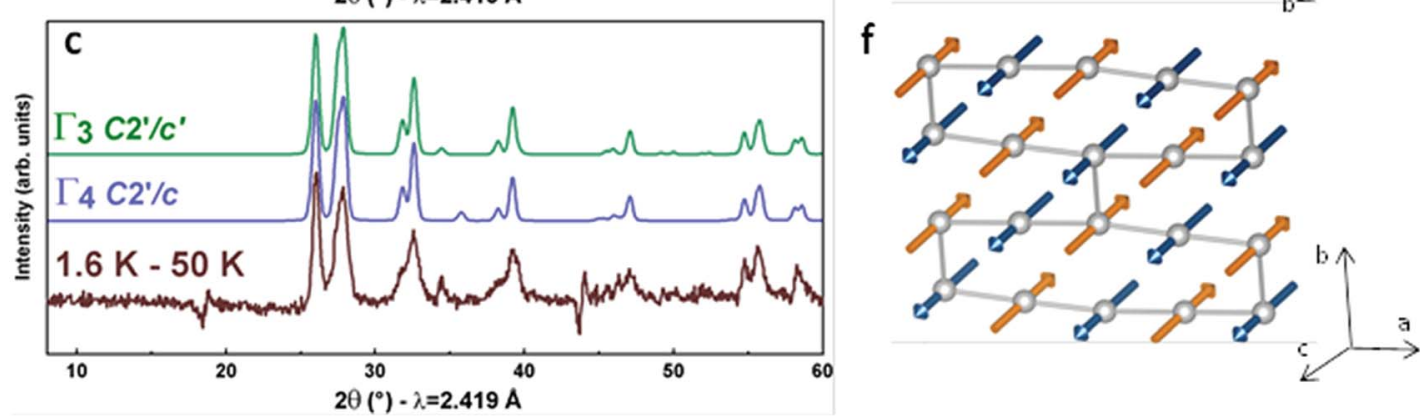

Fig. 13 Magnetic structure of $\mathrm{KFeSO}_{4} \mathrm{~F}$. (a and b) Results of the refinement of the nuclear and magnetic parts of the neutron powder diffraction pattern measured at $1.6 \mathrm{~K}$, with the $\Gamma_{3}$ and $\Gamma_{4}$ representations. The red crosses and the black line represent the experimental and the calculated patterns, respectively. The green line is the difference curve of these two patterns. The first line of blue sticks corresponds to the Bragg positions of the nuclear part while the second line of blue sticks shows the position of the expected magnetic reflections. (c) Comparison between the experimental difference pattern $(1.6-50 \mathrm{~K})$ and the magnetic contribution obtained with the two models. (d and e) View of the two magnetic structures corresponding to $\Gamma_{3}$ and $\Gamma_{4}$, respectively, both of them have in common an antiferromagnetic arrangement within a layer (f). Arrows represent the magnetic moments carried by iron atoms (grey balls); for the sake of clarity only Fe atoms and Fe-Fe bonds are represented. Note that the Shubnikov group $\mathrm{C2}^{\prime} / \mathrm{C}$ associated with $\Gamma_{4}$ contains the time reversal symmetry, so that $\mathrm{KFeSO}_{4} \mathrm{~F}$ may present magnetoelectric properties in its magnetically ordered phase, while it will not be the case if the magnetic structure is $C 2^{\prime} / c^{\prime}\left(\Gamma_{3}\right)$. 
$C 2^{\prime} / c^{\prime}$ and $\left.C 2^{\prime} / c\right)$ differ only in the $2 \theta$ region $\left[33-35^{\circ}\right]$ and powder diffraction cannot give a definite answer.

Both models consist of an antiferromagnetic arrangement in the layers, as seen in Fig. 13f. Whatever their connections, i.e. through F-vertices, O-vertices or $\mathrm{O}-\mathrm{O}$ edges, adjacent magnetic moments are antiparallel and the topology presents no geometrical frustration. $\Gamma_{3}\left(C 2^{\prime} / c^{\prime}\right)$ and $\Gamma_{4}\left(C 2^{\prime} / c\right)$ differ in the way the layers are stacked, which corresponds to the way magnetic moments are transformed by the inversion operator. For the former, $\mathrm{Fe}^{2+}$ magnetic moments linked through inversion are maintained parallel while they are antiparallel for the latter. At this stage, the interesting feature of this magnetic structure $C 2^{\prime} / c$ (representation $\Gamma_{4}$ ) is that the character of the inversion center $\left(\chi_{2}(g)=\chi_{2}(\overline{1})=-1\right)$ is negative, so the spatial inversion is associated with time reversal (the operator $\overline{1}^{\prime}$ belongs to $C 2^{\prime} / c$ ). This allows the linear magnetoelectric effect to be active below the Néel temperature. Therefore, if the magnetic structure follows $\Gamma_{4}$ $\left(C 2^{\prime} / c\right)$, an applied electric field may induce magnetization or an applied magnetic field may lead to electrical polarization. Such a specific magnetic structure has already been recently reported in $\mathrm{Li}_{2} \mathrm{Ni}\left(\mathrm{SO}_{4}\right)_{2} \cdot{ }^{19}$ Single crystals are needed to fully elucidate this point and eventually measure the magnetoelectric properties of this compound at low temperature.

\section{Conclusion}

A new low temperature $\mathrm{KFeSO}_{4} \mathrm{~F}$ phase was successfully synthesized and its electrochemical performance was tested. This new polymorph crystallizes in a large monoclinic $C 2 / c$ unit cell and presents a complex layered structure. The lower electrochemical performances of the monoclinic phase compared to its orthorhombic high temperature counterpart can be explained by the higher density of the former as well as by its higher activation energy and its highly limiting geometrical diffusion pathways as revealed by BVEL calculations. Even though the electrochemistry of this new polymorph stands back compared to other polyanionic materials such as $\mathrm{LiFePO}_{4}$ (theoretical energy density of $\sim 590 \mathrm{~W} \mathrm{~h} \mathrm{~kg}^{-1}$ for $\mathrm{LiFePO}_{4} v s$. $\sim 550 \mathrm{~W} \mathrm{~h} \mathrm{~kg}{ }^{-1}$ for $\mathrm{KFeSO}_{4} \mathrm{~F}$ ), its stabilization confirms once more the richness of polymorphism of sulfate-based phases in terms of their various structures and electrochemical behavior. Moreover, the exploration of the possible magnetic structures for $\mathrm{KFeSO}_{4} \mathrm{~F}$ indicates that it could be a magnetoelectric compound. Such physical properties will be worth exploring in the future.

\section{Acknowledgements}

We thank J. Rodriguez-Carvajal for many fruitful discussions, and V. Pomjakushin and T. Hansen for their help during neutron diffraction experiments. M. Courty is acknowledged for performing DSC measurements. Use of the 11-BM mail service of the APS at Argonne National Laboratory was supported by the
U.S. Department of Energy under Contract DE-AC0206CH11357 and is acknowledged. L. L. thanks the ANR "Hipolite" for the PhD funding and G. R. thanks the staff of the lowtemperature platform at UPMC.

\section{References}

1 A. K. Padhi, K. S. Nanjundaswamy and J. B. Goodenough, J. Electrochem. Soc., 1997, 144, 1188-1194.

2 C. Masquelier and L. Croguennec, Chem. Rev., 2013, 113, 6552-6591.

3 A. K. Padhi, V. Manivannan and J. B. Goodenough, J. Electrochem. Soc., 1998, 145, 1518-1520.

4 M. Reynaud, M. Ati, B. C. Melot, M. T. Sougrati, G. Rousse, J.-N. Chotard and J.-M. Tarascon, Electrochem. Commun., 2012, 21, 77-80.

5 L. Lander, M. Reynaud, G. Rousse, M. T. Sougrati, C. LabertyRobert, R. J. Messinger, M. Deschamps and J.-M. Tarascon, Chem. Mater., 2014, 26, 4178-4189.

6 N. Recham, J.-N. Chotard, L. Dupont, C. Delacourt, W. Walker, M. Armand and J.-M. Tarascon, Nat. Mater., 2010, 9, 68-74.

7 P. Barpanda, M. Ati, B. C. Melot, G. Rousse, J.-N. Chotard, M.-L. Doublet, M. T. Sougrati, S. A. Corr, J.-C. Jumas and J.-M. Tarascon, Nat. Mater., 2011, 10, 772-779.

8 M. Ati, B. C. Melot, J.-N. Chotard, G. Rousse, M. Reynaud and J.-M. Tarascon, Electrochem. Commun., 2011, 13, 1280-1283.

9 M. Ati, M. Sathiya, S. Boulineau, M. Reynaud, A. M. Abakumov, G. Rousse, B. C. Melot, G. van Tendeloo and J.-M. Tarascon, J. Am. Chem. Soc., 2012, 134, 1838018387.

10 I. Tordjman, R. Masse and J. C. Guitel, Z. Kristallogr., 1974, 139, 103-115.

11 N. Recham, G. Rousse, M. T. Sougrati, J.-N. Chotard, C. Frayret, S. Mariyappan, B. C. Melot, J.-C. Jumas and J.-M. Tarascon, Chem. Mater., 2012, 24, 4363-4370.

12 M. Anji Reddy, V. Pralong, V. Caignaert, U. V. Varadaraju and B. Raveau, Electrochem. Commun., 2009, 11, 1807-1810.

13 C. V. Subban, M. Ati, G. Rousse, A. M. Abakumov, G. van Tendeloo, R. Janot and J.-M. Tarascon, J. Am. Chem. Soc., 2013, 135, 3653-3661.

14 M. Ati, M. T. Sougrati, N. Recham, P. Barpanda, J.-B. Leriche, M. Courty, M. Armand, J.-C. Jumas and J.-M. Tarascon, J. Electrochem. Soc., 2010, 157, A1007-A1015.

15 H. M. Rietveld, J. Appl. Crystallogr., 1969, 2, 65-71.

16 J. Rodriguez-Carvajal, FullProf Suite, all the programs can be obtained from, http://www.ill.eu/sites/fullprof.

17 J. Rodriguez-Carvajal, Phys. B, 1993, 192, 55-69.

18 S. Adams, Solid State Ionics, 2006, 177, 1625-1630.

19 M. Reynaud, J. Rodriguez-Carvajal, J.-N. Chotard, J.-M. Tarascon and G. Rousse, Phys. Rev. B: Condens. Matter Mater. Phys., 2014, 89, 104419. 